\title{
Biotic and spatial factors potentially explain the susceptibility of forests to direct hurricane damage
}

\author{
Daehyun Kim ${ }^{1,2^{*}}$ (D) Andrew C. Millington ${ }^{3}$ and Charles W. Lafon ${ }^{4}$
}

\begin{abstract}
Background: Ecologists continue to investigate the factors that potentially affect the pattern and magnitude of tree damage during catastrophic windstorms in forests. However, there still is a paucity of research on which trees are more vulnerable to direct damage by winds rather than being knocked down by the fall of another tree. We evaluated this question in a mixed hardwood-softwood forest within the Big Thicket National Preserve (BTNP) of southeast Texas, USA, which was substantially impacted by Hurricane Rita in September 2005.

Results: We showed that multiple factors, including tree height, shade-tolerance, height-to-diameter ratio, and neighborhood density (i.e., pre-Rita stem distribution) significantly explained the susceptibility of trees to direct storm damage. We also found that no single factor had pervasive importance over the others and, instead, that all factors were tightly intertwined in a complex way, such that they often complemented each other, and that they contributed simultaneously to the overall susceptibility to and patterns of windstorm damage in the BTNP.

Conclusions: Directly damaged trees greatly influence the forest by causing secondary damage to other trees. We propose that directly and indirectly damaged (or susceptible) trees should be considered separately when assessing or predicting the impact of windstorms on a forest ecosystem; to better predict the pathways of community structure reorganization and guide forest management and conservation practices. Forest managers are recommended to adopt a holistic view that considers and combines various components of the forest ecosystem when establishing strategies for mitigating the impact of catastrophic winds.
\end{abstract}

Keywords: Disturbance, Hurricane Rita, Life history traits, Neighborhood density, Spatial point pattern analysis

\section{Background}

Catastrophic wind disturbances, even though infrequent, exert profound influences on many aspects of forest ecology, including stand age, species composition, regeneration, and nutrient cycling (Webb 1989; Foster and Boose 1992; Everham and Brokaw 1996; Lafon 2006; Mitchell 2013). However, these characteristics are challenging to investigate because the three-dimensional patterns of windstorm damage on trees are generally complex (Ulanova 2000; Xi and Peet 2011). A poststorm forest stand appears chaotic at first sight because

\footnotetext{
* Correspondence: biogeokim@snu.ac.kr

'Department of Geography, Seoul National University, Seoul 08826, South Korea

${ }^{2}$ Institute for Korean Regional Studies, Seoul National University, Seoul 08826,

South Korea

Full list of author information is available at the end of the article
}

many trees of different species and sizes are uprooted, snapped at different heights, bent or leaning in various directions, etc. In this study, we explicitly distinguished between direct damages and indirect damages, the latter being caused by the fall of another tree. We posited that directly damaged individuals play a major role in the apparent disorder by causing secondary damage to other trees as they fall.

Previous research on wind disturbance to forests indicated that the direct aerodynamic impact of wind mainly affects tall, canopy trees, and that short, sub-canopy individuals are almost entirely sheltered from the direct effect of wind. Some of these sub-canopy individuals are damaged by larger, canopy trees falling on them during catastrophic wind events (Glitzenstein and Harcombe 1988; Clinton and Baker 2000; Peterson 2000; Canham et al. 2001; see Everham and Brokaw 1996 for a thorough list of 
relevant literature). As a result of the kinetic energy of their massive stems and canopies crashing through the lower forest strata, these directly impacted canopy trees influence the fate of many sub-canopy trees, and thereby govern the patterns of indirect sub-canopy tree damage. The patterns of direct damage may thus account for a large portion of post-storm carbon dynamics in a given forest (Zeng et al. 2004; Uriarte and Papaik 2007; Kooch et al. 2014; Santos et al. 2016). Overall, understanding the circumstances under which direct damage occurs to a tall, canopy tree will help to predict the pathways of community structure reorganization (Harcombe et al. 2009) and guide forest management and conservation practices (Franklin et al. 2002; Gardiner et al. 2005; Long 2009).

In this study, we focused specifically on the susceptibility of trees to direct damage (Clinton and Baker 2000; Batista and Platt 2003). Directly and indirectly damaged stems have often been confounded and treated as a single data set rather than being inventoried and analyzed separately. Accordingly, the current literature lacks studies that have evaluated the probability of direct damage in the context of the simultaneous effects and relative importance of multiple factors, such as tree height, shade-tolerance, height-to-diameter ratio (H:D), and neighborhood density (i.e., pre-storm tree distribution). We hypothesized that, under equal conditions (e.g., soil and topographic conditions, stand origin age, management history, and disease status), the probability of direct damage to trees increases with the following:

(a) Increasing height, due to greater exposure to high winds;

(b) A reduction in shade-tolerance, because of their lower investment in main stem wood strength;

(c) Increasing $\mathrm{H}: \mathrm{D}$, as trees with high $\mathrm{H}: \mathrm{D}$ have relatively thin main stems; and

(d) Greater distance between neighboring trees, since this can lead to greater air turbulence within the canopy.

A confounding issue with testing these hypotheses individually is that the relationships are not mutually exclusive. For example, in temperate and low-lying regions, shade-tolerant species are likely to be shorter and have lower H:D than shade-intolerant trees because they allocate more energy to diameter growth than height growth (Rich et al. 2007). Therefore, the strategies of shadetolerant trees lead to stem strength investments and potentially enhance windfirmness. Simply, all of these factors are related to, and represent, the life history traits of each tree species (Stearns 1992; Grime 2001; Valladares and Niinemets 2008). Therefore, it can further be hypothesized that, under similar environmental conditions, species identity is the integral representative factor that determines the vulnerability of a tree to direct wind damage during a catastrophic storm event.

\section{Materials and methods \\ Study area and Hurricane Rita}

We conducted this study in the Big Thicket National Preserve (BTNP) in east Texas, USA, which is located on the Gulf Coastal Plain (Fig. 1). The region is characterized by a humid continental climate with mean monthly temperatures ranging from $10^{\circ} \mathrm{C}$ (January) to $29^{\circ} \mathrm{C}$ (July and August) at Livingston $\left(30^{\circ} 43^{\prime} 1.4^{\prime \prime} \mathrm{N}\right.$ : $\left.94^{\circ} 56^{\prime} 32.9^{\prime \prime} \mathrm{W}\right)$ and a mean annual precipitation of $1309 \mathrm{~mm}$ (NOAA 2017). Most of the BTNP is located on the broad interfluves between the Trinity and Neches rivers. We sampled forests on the interfluves with a prevalent mix of oak (Quercus) and pine (Pinus) trees (Marks and Harcombe 1981). There was a diverse mix of species where the interfluves sloped gently toward the streams. The typical dominant species included loblolly pine (Pinus taeda), white oak (Quercus alba), American beech (Fagus grandifolia), southern magnolia (Magnolia grandiflora), and water oak (Quercus nigra). The lower slope forests gave way to floodplain hardwood forests and bald cypress (Taxodium distichum) in the lowest and wettest areas. Our study was focused entirely on the lower slope mixed forests in the BTNP. Ultisols are predominant in the coastal plain of the USA, but in the study forest, also important are alfisols on uplands and slopes and entisols (e.g., quartzipsamments) on floodplains (Marks and Harcombe 1981). These soils are generally fine-sandy loam (https://casoilresource.lawr.ucdavis.edu/gmap/; last accessed August 10, 2019).

The forests are periodically disturbed by tropical storms (Harcombe et al. 2009). Hurricane Rita extensively damaged the forests of the BTNP in September 2005. It made landfall on September 25, 2005 close to the Louisiana-Texas state line as a Category 3 system (peak winds ca. $200 \mathrm{~km} \mathrm{~h}^{-1}$ ), and was, at the time, the fourth largest Atlantic hurricane on record. The eye of the storm passed $\sim 16 \mathrm{~km}$ to the east of the forest plots later that day (Fig. 1).

\section{Forest survey}

Five 0.2-ha $(40 \times 50 \mathrm{~m})$ plots were established in the Turkey Creek Unit of the BTNP, $\sim 6$ weeks after Hurricane Rita (Additional file 1: Figure S1). This forest unit was not accessible until that time due to safety considerations. The sampling was designed for two purposes: to recreate the post-hurricane forest structure and to test the hypotheses outlined above through quantitative assessments of hurricane damage. The following information was determined for trees with trunks that were located within the plots at the time of the hurricane impact: 


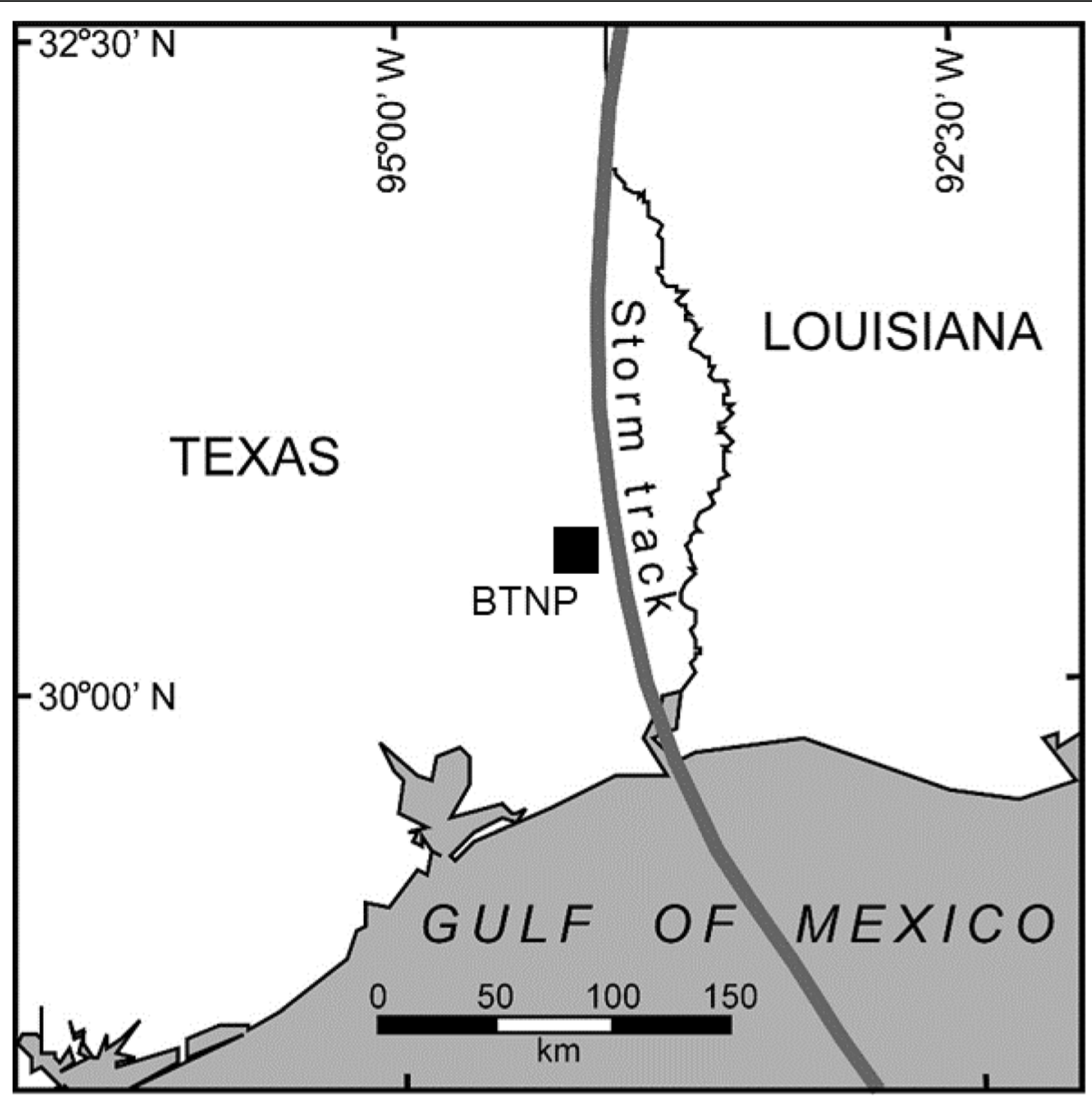

Fig. 1 The geographic location of the Big Thicket National Preserve (BTNP) in east Texas. The curve next to the BTNP site indicates the pathway of Hurricane Rita in September 2005

(a) The species;

(b) The spatial location ( $x$ and $y$ coordinates within each plot) of each trunk with a precision of $0.1 \mathrm{~m}$ using surveyor tape from plot corners, for which GPS coordinates had been collected;

(c) The diameter at breast height $(\mathrm{DBH})$ was taken at $1.3 \mathrm{~m}$ above the ground surface using a caliper log. Only trees with DBHs $\geq 5 \mathrm{~cm}$ were considered in this research;

(d) The height to the top of the canopy (HTT), see below;

(e) Assignment to one of five stem damage classes: undamaged, bent, leaning, snapped, and uprooted; and

(f) If the damage to trees was directly or indirectly caused.

The HTT of undamaged trees was determined using a clinometer. The angle to the top of each tree and the horizontal distance from the observer to the tree were recorded. The calculation of HTT was based on the Pythagorean theorem, with an adjustment for the height of the clinometer reader, i.e., a constant of $1.8 \mathrm{~m}$ was added since the same person recorded all clinometer measurements.

The following procedures were used when assigning trees to damage classes. The heights of uprooted trees were measured from the upper root plate to the top of the canopy using a loggers tape. For snapped trees, the height to the point of snapping was measured using a clinometer (see above), and then the snapped section (from the point of snapping to the top of the canopy) was measured using a loggers tape. Sometimes, this involved measuring multiple snapped sections. For trees allocated to the leaning damage category, the height to the top of the "leaning" tree was measured using the clinometer and adjusted using the angle of the lean relative to the vertical. For trees in the bent class, we photographed and drew the "shape" of the bent stem in a field notebook and measured heights from the ground to the bent stem at various points along the tree using a loggers tape. We also recorded where these vertical measurements were made along a horizontal line to describe 
the direction of the main stem. Then, by treating the bent stem as an arc of a circle, we computed the arc length using relevant equations (https://www.wolframal pha.com/examples/ArcLength.html; last accessed June 24, 2019).

Although we examined several tree characteristics, we recognize that these are not comprehensive and that there might be other influential factors. For example, some trees have multi-stemmed morphology (clones) as a result of resprouting after disturbance, whereas others are grown from a seedling, single-stemmed. Because the stems of the clone structure are connected together by roots, the response to disturbance should be different compared to single-stemmed trees. In addition, soil conditions (e.g., wetness, depth, and hardness) can also affect the susceptibility of trees to hurricane damage (e.g., Everham and Brokaw 1996). Among the five study plots we established (Additional file 1: Figure S1), plot 5 was most inundated and muddy. Plot 4 was also waterlogged occasionally, but plots 1,2 , and 3 were rarely flooded. Due to its topographic setting, plot 1 seemed to have two soil types: The northern end was generally flat, whereas the southern end was steeply sloping.

\section{Data analysis \\ Effect of tree height}

All HTT values were first classified into the following four categories, with $10 \mathrm{~m}$ intervals: 0-9.9, 10-19.9, 2029.9 , and $\geq 30 \mathrm{~m}$. In each of these classes, we estimated the relative proportion of three damage types: direct damage, indirect damage, and no damage. In this way, the probability of direct damage was examined as a function of varying HTTs. In addition, the proportion of each tree species was also calculated for each height class.

\section{Effect of shade-tolerance}

All species were classified into the following three categories according to their levels of tolerance to shade conditions: tolerant, moderately tolerant, and intolerant (see Burns and Honkala 1990; Additional file 1: Table S1). In each of these classes, we estimated the relative proportion of three damage types: direct damage, indirect damage, and no damage. Hence, the probability of direct damage was examined as a function of varying levels of shade-tolerance. We repeated this same analysis after separating all tree individuals into two broad height categories based on HTTs: $0-19.9 \mathrm{~m}$ and $\geq 20 \mathrm{~m}$. This data division allowed us to control for the effect of height and thereby better clarify the relationship between shade-tolerance and direct damage.

\section{Effect of height-to-diameter ratio}

All tree stems, regardless of species identity, were classified into the following three categories of $\mathrm{H}: \mathrm{D}$ : low, medium, and high. To our knowledge, there was no specific guideline or criterion regarding this type of classification in the literature. Thus, we simply rank-ordered all surveyed trees based on their $\mathrm{H}: \mathrm{D}$, and then distributed them into the three classes, such that each class possessed the same number of trees (or a similar number of trees in cases where the total number was not divisible by three). In each category, we estimated the relative proportion of damage types (i.e., direct damage, indirect damage, and no damage) to examine the probability of direct damage as a function of varying H:D. In addition, the proportion of each tree species was calculated for each class. Finally, we attempted to further understand the relationships between $\mathrm{H}: \mathrm{D}$ and direct damage by separating all tree individuals into two broad HTT categories (i.e., $0-19.9 \mathrm{~m}$ and $\geq 20 \mathrm{~m}$ ).

\section{Effect of neighborhood density}

We hypothesized that a wide spacing of trees would increase the possibility of direct damage as a result of increased air turbulence within the open canopy (see the "Background" section; it is also possible that H:D is lowered by wide spacing and this might increase resistance to stem breakage). Therefore, an important consideration is whether tall canopy trees, rather than short, understory counterparts, are densely or sparsely distributed throughout a forest. It is presumed that the aggregation of small individuals around a large tree is not likely to influence the vulnerability of the large tree to direct damage. Therefore, only those trees with HTTs $\geq$ $20 \mathrm{~m}$ were considered for the spatial analysis in the present study.

As a first step, a toroidal correction was performed to avoid the potential problem of edge effects; assuming that bordering forest stands around each plot had similar tree distributions to the plot (Haase 1995). Edge effects were expected when estimating the neighborhood density for stems that were located close to the plot margins. The inter-tree Euclidean distance was then measured for every pair of individuals.

We examined the pre-Rita distribution of tall, canopy trees in each plot at multiple spatial scales using sampling areas with the following radii (i.e., neighborhood size): $3,6,9,12,15$, and $18 \mathrm{~m}$. These examinations involved drawing circles around each stem using these radii and then counting the number of other stems located within the areas. At each scale, we identified the maximum number of neighbors to define three categories of neighborhood density: low, medium, and high. For example, if the maximum number was found to be 8 at a certain scale, each class would be defined as follows:

(a) Low density $=0,1$, and 2 neighbors (i.e., 3 types) 


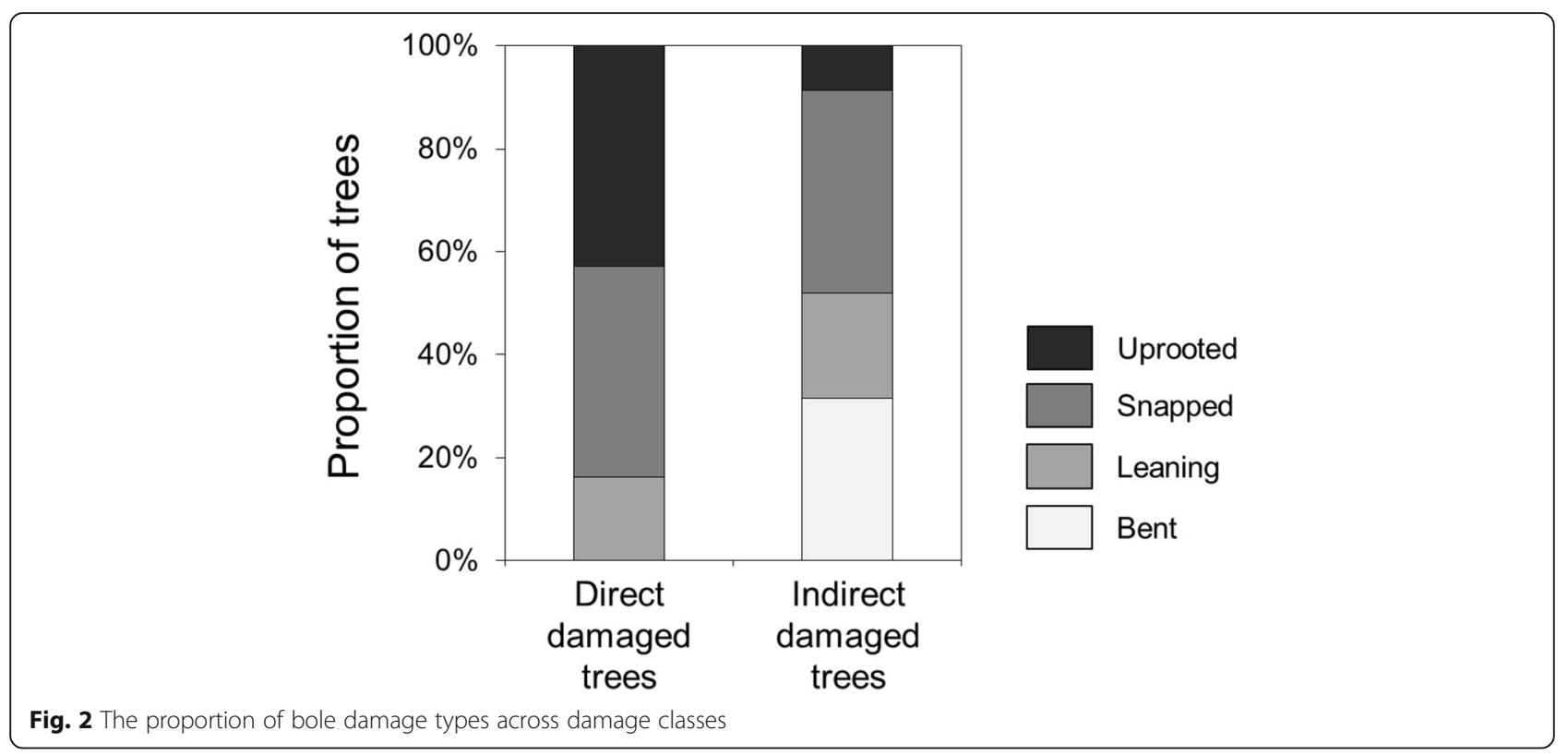

(b) Medium density $=3$, 4, and 5 neighbors (i.e., 3 types)

(c) High density $=6,7$, and 8 neighbors (i.e., 3 types)

If the maximum number was 9:

(a) Low density $=0$, 1 , and 2 neighbors (i.e., 3 types) (b) Medium density $=3$, 4, and 5 neighbors (i.e., 3 types)

(c) High density $=6,7,8$, and 9 neighbors (i.e., 4 types)

If the maximum number was 10 :

(a) Low density $=0$, 1, and 2 neighbors (i.e., 3 types)

\section{(a)}



\section{(b)}

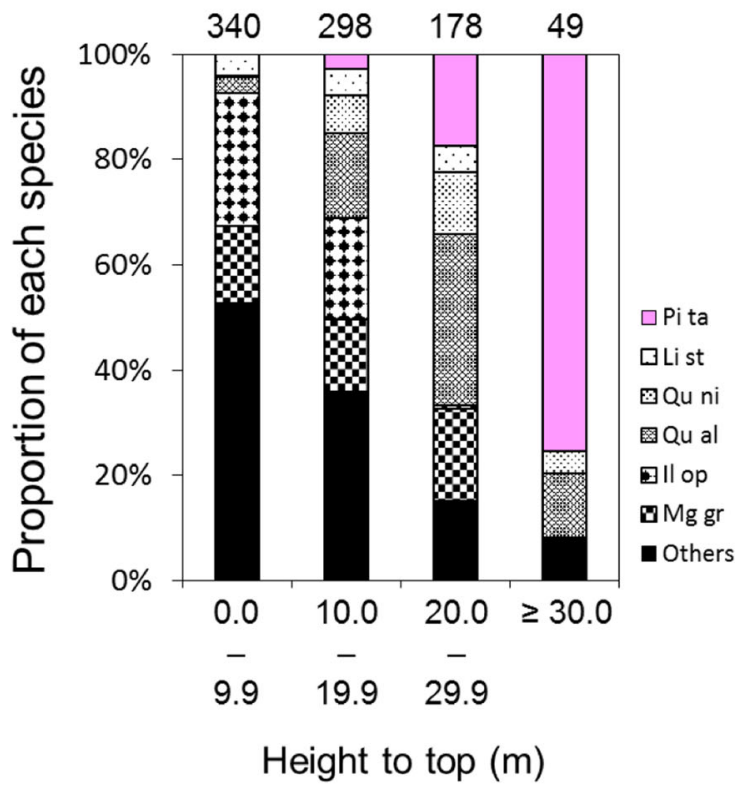

Fig. 3 a The proportion of three damage types across tree height classes. $\mathbf{b}$ The proportion of the main tree species across height classes. Each value on top of the bars indicates the number of stems within each height category (Pi ta = Pinus taeda, Li st = Liquidambar styraciflua, Qu ni = Quercus nigra, Qu al = Quercus alba, II op = llex opaca, Mg gr= Magnolia grandiflora) 
(b) Medium density $=3,4$, 5, and 6 neighbors (i.e., 4 . types)

(c) High density = 7, 8, 9, and 10 neighbors (i.e., 4 types)

This method enabled us to assign, whenever possible, more weight to higher-density categories because there were always many more trees within the lower-density classes than within their higher-density counterparts. In each category, we finally estimated the relative proportion of two damage types, that is, direct damage and the others. The latter estimates were a combination of indirect damage and no damage types. Thus, the probability of direct damage could be determined as a function of varying neighborhood density.

\section{Effect of species identity}

The two most abundant tree species from each of the three shade-tolerance groups (i.e., tolerant, moderately tolerant, and intolerant) were selected. We estimated the relative proportion of damage types (i.e., direct damage, indirect damage, and no damage) for each of these six species to examine if the probability of direct damage varied among species. We repeated this same procedure after separating all tree individuals into two broad categories based on their HTTs: $0-19.9 \mathrm{~m}$ and $\geq 20 \mathrm{~m}$.

\section{Significance test}

All of the five factors (HTT, shade-tolerance, H:D, neighborhood density, and species identity) were subjected to G-tests with William's correction to evaluate the significance of their effect on the probability to direct damage (Sokal and Rohlf 1995). Also, when it was necessary to compare the average values of the factors across different categories, we utilized a one-way analysis of variance (ANOVA). All statistical evaluations were conducted at the $p<0.10$ significance level.

\section{Results}

Overall, we surveyed a total of 865 trees comprising 38 species (see Additional file 1: Figures S2 and S3 for the spatial distribution of trees and species composition within each plot). Among these, the species identity of 30 individuals was unidentifiable. As a result of Hurricane Rita, 49 and 171 trees suffered direct and indirect damages, respectively. In the direct damage category, there were no bent trees, while more than $40 \%$ was explained by uprooted individuals (Fig. 2). The proportion of uprooted trees dramatically decreased $(<10 \%)$ in the indirect damage class, whereas bent stems accounted for more than $30 \%$. The average HTT of the directly damaged trees was $19.5 \mathrm{~m}$. This value was almost consistent with the cutoff level (i.e., $20 \mathrm{~m}$ ) for broadly classified trees (into two categories). The average HTT of the indirectly damaged trees was $12.5 \mathrm{~m}$.

\section{Effect of tree height}

As expected, there was a significant height effect on the probability of direct damage by Hurricane Rita $\left(G_{\text {ad- }}\right.$ justed $=37.396, p<0.0001$; Fig. 3a). The vulnerability increased with increasing HTT until the third category (20-29.9 m), which had the greatest proportion of $Q$. alba and Q. nigra (combined, 44.4\%) among all classes $\left(G_{\text {adjusted }}=533.030, p \approx 0\right.$; Fig. $\left.3 \mathrm{~b}\right)$. This positive relationship, however, was not observed in the highest category (HTT $\geq 30 \mathrm{~m}$ ). Among the total 49 trees in this group, 37 individuals were $P$. taeda (i.e., 75.5\%); none of which

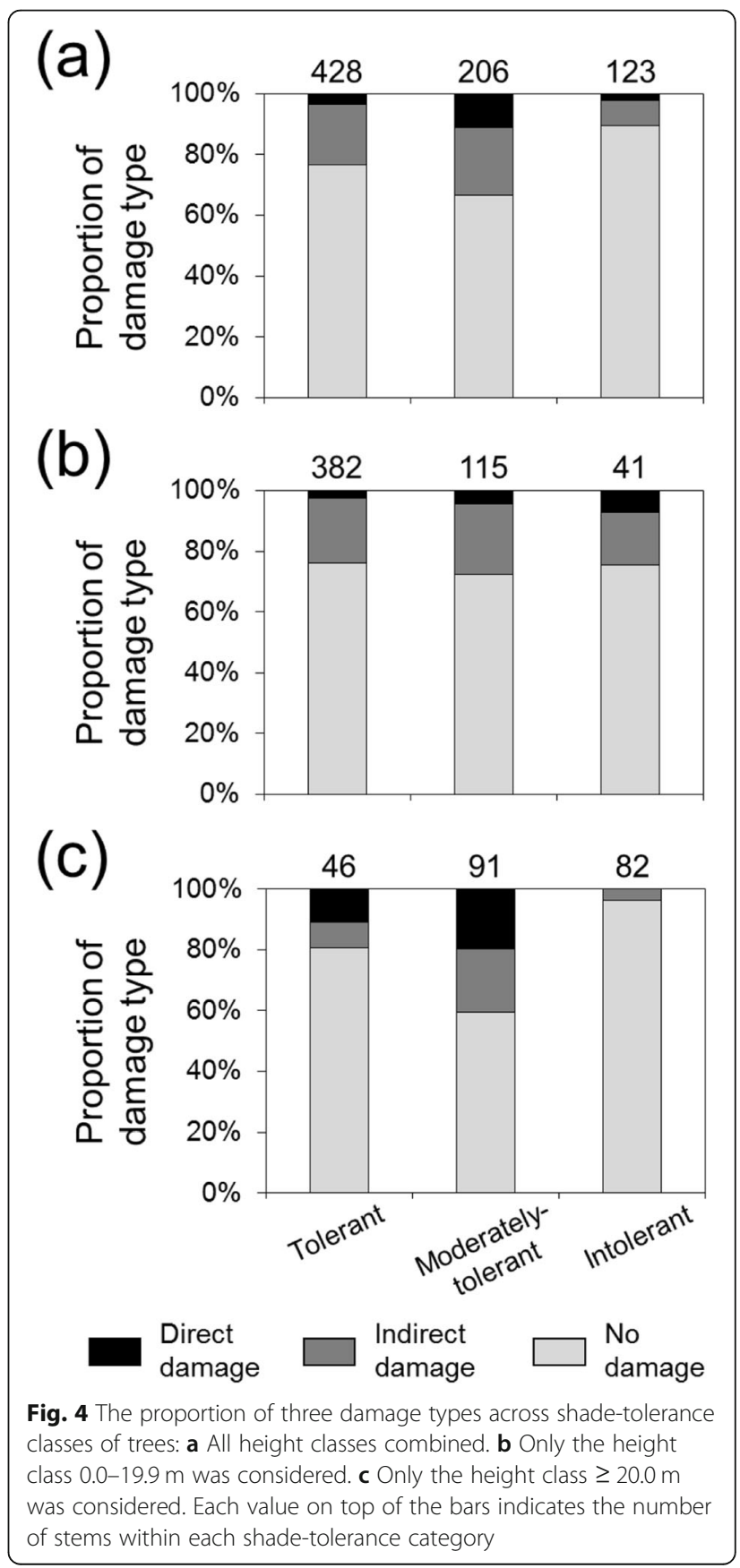


had been damaged either directly or indirectly by the windstorm. The average DBH of these large pine trees was $45.4 \mathrm{~cm}$.

\section{Effect of shade-tolerance}

The susceptibility to direct damage significantly differed across the levels of shade-tolerance tested $\left(G_{\text {adjusted }}=\right.$ $31.335, p<0.0001$; Fig. 4a). Different from the initial expectation, however, the intolerant category exhibited the least direct damage whereas the greatest probability was detected in the moderate-tolerant class. Pinus taeda was the dominating species $(61.8 \%)$ in the intolerant species group, and in the moderately tolerant class, both Q. alba and $Q$. nigra were the most abundant (combined, 81.6\%). These inter-level differences became insignificant when only the trees with HTTs of $0-19.9 \mathrm{~m}$ were considered $\left(G_{\text {adjusted }}=3.065, p=0.547\right.$; Fig. $\left.4 \mathrm{~b}\right)$. In contrast, a clearer and significant differentiation among the three categories was detected $\left(G_{\text {adjusted }}=41.512, p<0.0001\right)$ in the larger tree group (i.e., HTTs $\geq 20 \mathrm{~m}$; Fig. 4c).

\section{Effect of height-to-diameter ratio}

Although the H:D had a significant influence on the chance of direct damage, the trend across the three categories opposed the initial expectation $\left(G_{\text {adjusted }}=\right.$ $25.950, p<0.0001$; Fig. $5 \mathrm{a}$ ), whereby the probability of direct damage increased as the ratio decreased. Notably, the decrease of the H:D corresponded to increases in both the average HTT (from 12.1 to $17.5 \mathrm{~m}$; one-way ANOVA $F=31.938, p<0.0001)$ and the proportion of $Q$. alba and $Q$. nigra (from $10.7 \%$ to $39.1 \%$; $G_{\text {adjusted }}=$ 86.670, $p<0.0001$; Fig. 5b). These inter-level differences were still significant after the trees were separated into the two broad HTT groups (all G-tests $p$ values $<0.05$; Fig. 5 c, d), but a clearer differentiation among the categories was only observed when the larger tree group (i.e., HTT $\geq 20 \mathrm{~m}$ ) was considered.

\section{Effect of neighborhood density}

In general, the effects of neighborhood density were clearly consistent with the initial expectations for all of the six spatial scales tested (Fig. 6), whereby the probability of direct damage was higher when there was a low density. Statistically, however, this relationship was significant only at the 6,9 , and $15 \mathrm{~m}$ radii.

\section{Effect of species identity}

The probability of direct damage by Hurricane Rita varied significantly among the different species $\left(G_{\text {adjusted }}=\right.$ 41.973, $p<0.0001$; Fig. 7a). In this analysis, only two main species were considered from each of the three shade-tolerance categories: $M$. grandiflora and Ilex

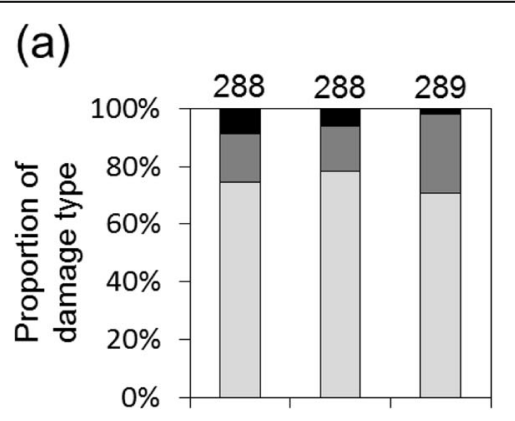

(c)



(b)

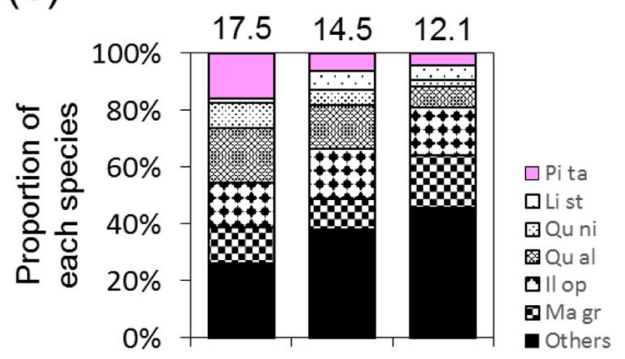

(d)

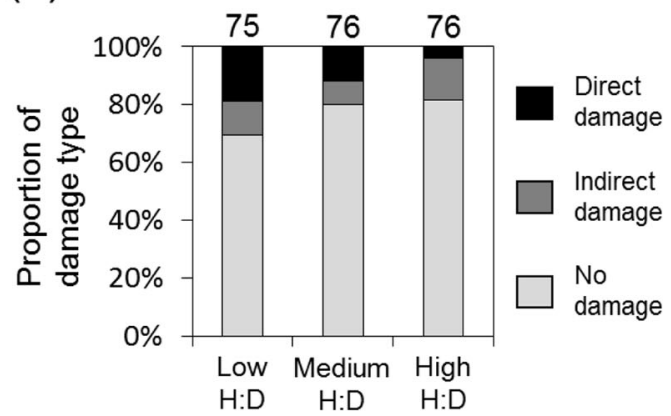

Fig. 5 The proportion of three damage types across the height-to-diameter ratio $(\mathrm{H}: \mathrm{D})$ classes of trees in the sampled sites in the Big Thicket National Preserve: a All height classes combined. c Only the height class 0.0-19.9 m was considered. d Only the height class $\geq 20.0 \mathrm{~m}$ was considered. Each value on top of the bars indicates the number of stems within each $\mathrm{H}: \mathrm{D}$ category. $\mathbf{b}$ The proportion of main tree species across the $\mathrm{H}: \mathrm{D}$ classes. Each value on top of the bars indicates the mean height to top $(\mathrm{m})$ of stems within each $\mathrm{H}: \mathrm{D}$ category $(\mathrm{Pi}$ ta $=$ Pinus taeda, $\mathrm{Li}$ $\mathrm{st}=$ Liquidambar styraciflua, Qu ni=Quercus nigra, Qu al = Quercus alba, II op = llex opaca, Mg gr= Magnolia grandiflora) 

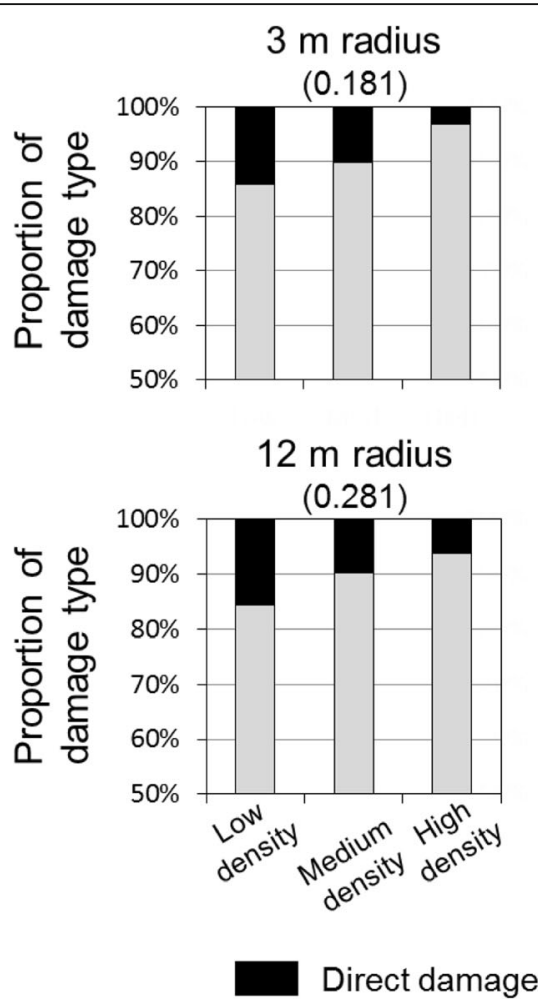

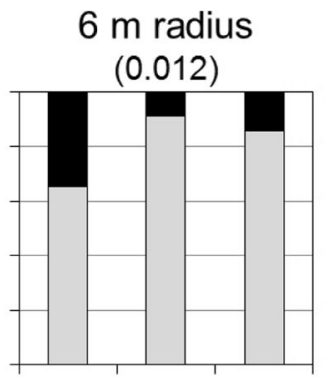

$15 \mathrm{~m}$ radius $(0.047)$

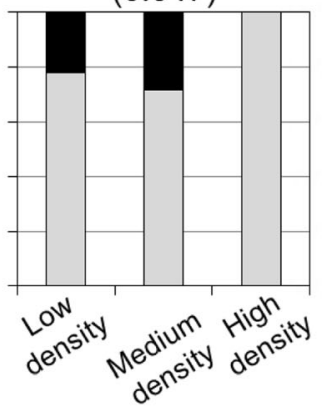

$9 \mathrm{~m}$ radius

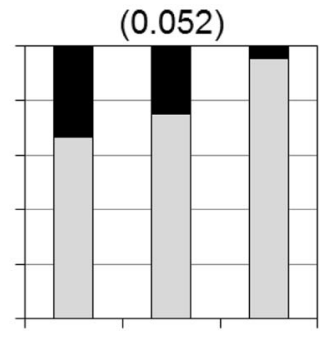

$18 \mathrm{~m}$ radius (0.501)

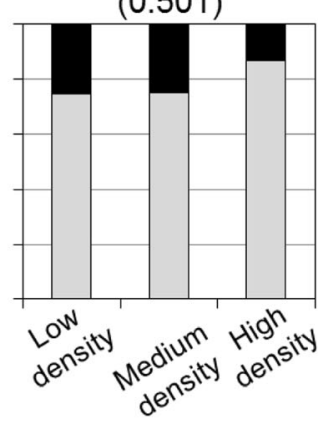

Other (indirect + no damage)

Fig. 6 The proportion of damage types across neighborhood density classes of trees in the sampled sites in the Big Thicket National Preserve, at multiple spatial scales. Each value in the parentheses indicates the $p$ value produced by the G-test at each sampling area radius

opaca from the tolerant class, Q. alba and Q. nigra from the moderately tolerant class, and Liquidambar styraciflua and P. taeda from the intolerant category. Quercus alba and $Q$. nigra showed a greater vulnerability to direct damage than the other species. These inter-species differences were still significant after separating all trees into the two broad HTT groups (all G-tests $p$ values < 0.05; Fig. 7b, c), but the direct damages to $Q$. alba and $Q$. nigra were more clearly detected when only the larger tree group (i.e., HTT $\geq 20 \mathrm{~m}$ ) was considered.

\section{Discussion}

\section{Factors affecting the probability of direct damage}

All factors considered in this research seem to influence the vulnerability of trees to direct damage by Hurricane Rita. Our findings were not always consistent with our initial expectations, e.g., we did not observe the highest possibility of direct damage from the trees belonging to (a) the greatest height class, (b) the shade-intolerant group, and (c) the high H:D category. In addition, the effect of neighborhood density was not invariably significant across all assessed spatial scales. These unexpected findings appeared to have been associated with species identity. In particular, the relative proportion of the three species, Q. alba, Q. nigra, and P. taeda, was the key to predicting whether a category was characterized as highly susceptible to direct wind damage or not. These two oak species occupied a dominant portion of the classes of 20-30 m HTT (44.4\%), moderate shadetolerance (81.6\%), and low H:D (39.1\%), and these categories consistently exhibited greater probabilities of direct damage compared to the other categories.

In contrast, trees in the HTT $\geq 30 \mathrm{~m}$ and shadeintolerant classes showed a low chance of direct damage, most likely due to the predominance of $P$. taeda (and accordingly, low proportions of $Q$. alba and $Q$. nigra) within these classes. In several previous studies, pine trees have been reported to be (highly) susceptible to storm damage (e.g., Foster 1988; Glitzenstein and Harcombe 1988; Gresham et al. 1991; Xi et al. 2008). For example, Glitzenstein and Harcombe (1988) found that more than half of all inventoried loblolly pines in the BTNP, especially those with large DBHs, had been severely damaged or killed by a tornado in December 1983. The contrasting results between this previous study and the present study can be explained by the different community settings: the tornado research was conducted in a relatively open savanna wherein the large individuals of $P$. taeda, which overtopped understory hardwoods, were exposed to the direct forces of the wind, whereas our post-Rita plots were established in 

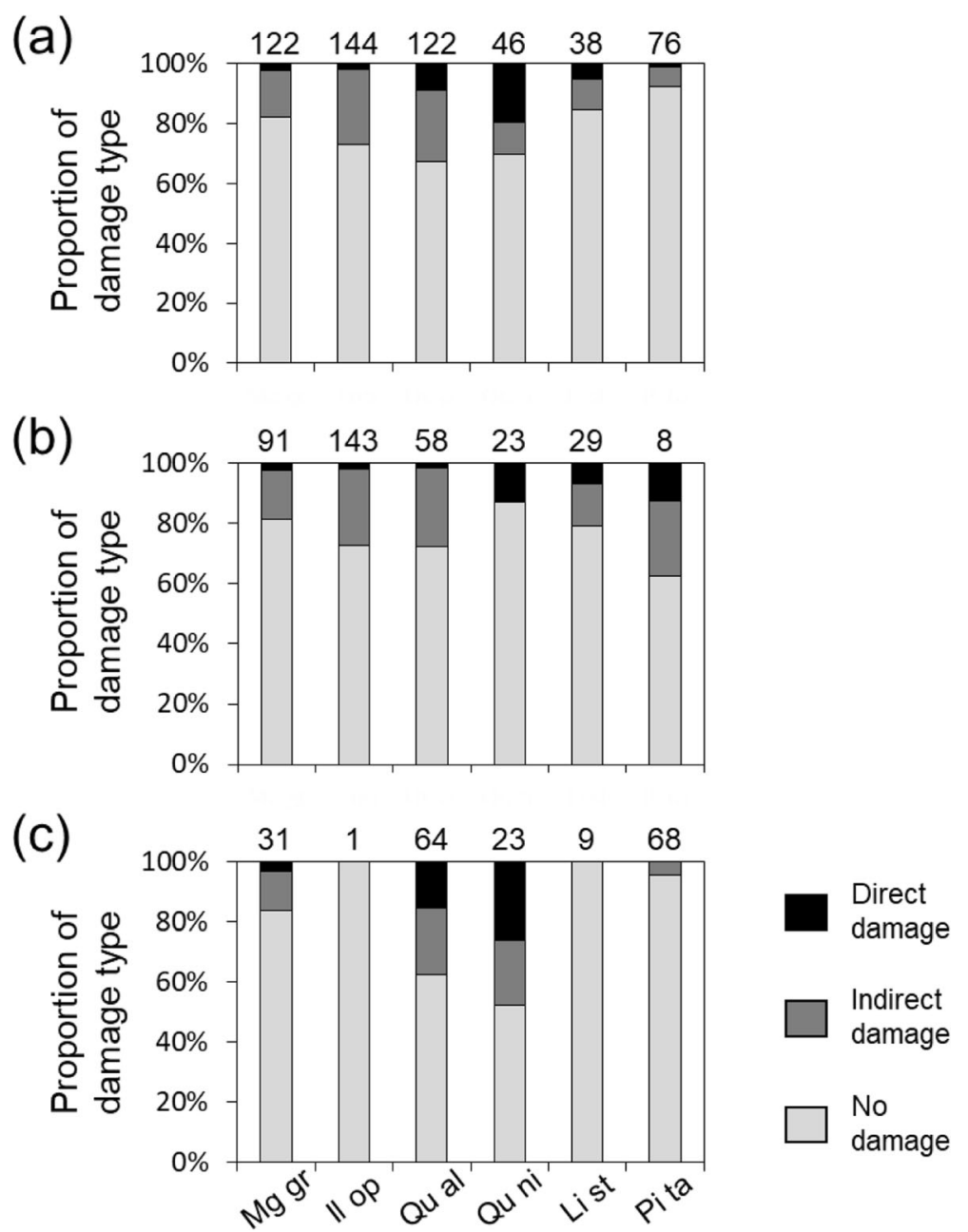

Fig. 7 The proportion of three damage types across the main tree species in the sampled sites in the Big Thicket National Preserve: a All height classes combined. b Only the height class 0.0-19.9 m was considered. c Only the height class $\geq 20.0 \mathrm{~m}$ was considered. Each value on top of the bars indicates the number of stems within each species category (Mg gr= Magnolia grandiflora, $\|$ op = llex opaca, Qu al = Quercus alba, Qu ni= Quercus nigra, Li st = Liquidambar styraciflua, Pi ta $=$ Pinus taeda)

dense, mixed forest stands in which many large hardwoods and softwoods coexisted (see Harcombe et al. 2009 for more discussion).

In summary, species identity appeared to be the main factor that helped to determine the vulnerability of trees in the BTNP plots to direct damage during Hurricane Rita. This conclusion advances, rather than invalidates, the general notion that tree size greatly governs damage patterns resulting from windstorms (e.g., Peterson 2000; Canham et al. 2001; Ancelin et al. 2004; Wolf et al. 2004; Allen et al. 2012). We propose that the size-damage relationship will become more useful when researchers, especially those dealing with multi-species stands, appreciate the importance of considering species individually (Harcombe et al. 2009). As demonstrated in the P. taeda example above, the resistance of a species may differ depending on the type of stand structure it is situated in (Everham and Brokaw 1996).

\section{Insights from detailed spatial analysis}

Among the abovementioned factors, the role of the prestorm tree distribution in generating damage patterns has remained relatively underrepresented and unresolved in the literature (Gardiner et al. 1997). In a physiological sense, and if all other factors are held constant (e.g., species identity, topographic position, soil condition, wind speed and direction, and time since last storm), a wide inter-tree spacing is generally believed to reduce the intensity of competition, thereby allowing individual trees to maintain active (diameter) growth (Pinkard and Neilsen 2003; Egbäck et al. 2015). This will likely decrease their susceptibility to direct windstorm damage 
(Cremer et al. 1982; Peltola and Kellomäki 1993; Oliver 1997; Valinger and Fridman 1997; Wonn and O'Hara 2001). In contrast, and considering the aerodynamic factors, wide spacing is well known to enhance the risk of direct damage by inducing (1) greater forces on trees driven by increased air turbulence within the open canopy and (2) increased swaying of individual stems due to the lack of close neighbors (Green et al. 1995; Milne 1995; Hale et al. 2012; Ruck et al. 2012).

Inter-tree spacing has long been an important topic among forest managers (Mason 2002; Gardiner et al. 2005; Schindler et al. 2012). A fundamental question is whether or not regularity should be enhanced in the distribution of trees within a forest to reduce the risk of windstorm damage in susceptible areas. The results of our spatial point pattern analysis clearly indicated that direct damage by catastrophic wind disturbance during Hurricane Rita was not a spatially random process and that the susceptibility increased when the tall canopy trees of interest $(\mathrm{HTT} \geq 20 \mathrm{~m})$ were isolated from similar-sized (or taller) neighbors, supporting the aerodynamic notion above.

Spatial factors, such as neighborhood density and inter-tree spacing, have been of primary concern in many previous studies, but spatially explicit analytic techniques (e.g., point pattern analysis, fractals, mantel test, and autocorrelation) are still not widely employed based on detailed, exhaustive surveys of the spatial coordinate of all individual tree stems within a stand. To the best of our knowledge, we conducted the first spatial analysis at such a detailed level across multiple forest plots to investigate the effects of pre-storm patterns of tree distribution on the probability of direct wind damage (cf. Condit et al. 2000; Wiegand and Moloney 2004, 2013; Churchill et al. 2013; Kim and Campbell 2016).

\section{Conclusions}

The basic premise of this research was that directly damaged trees, being mostly tall, canopy individuals, are the key drivers of overall post-storm forest structure and subsequent regeneration pathways. However, indirectly damaged trees should not be considered to be of less importance or concern to disturbance ecologists. It would be reasonable to analyze both damage types together if the aim was to understand the total impact caused by a storm. However, when determining which trees are more vulnerable to direct damage, different approaches should be used. For example, the direct and indirect impacts of a windstorm occur in a chain-reaction mode, like falling dominoes, which typically results in the spatial aggregation of damaged trees (Webb 1988; Clinton and Baker 2000). Because such aggregations are evident when trees are closely spaced, several ecologists initially proposed that storm damage should increase with increasing stand density (e.g., Reukema 1970,
1979; Cremer et al. 1982). While this may be true if the degree of damage is represented solely by the number of all fallen stems, confounding the two damage types would impede our ability to answer under what spatial context trees are more likely to be directly impacted (Webb 1989; Peterson 2000).

Many factors have been suggested to influence damage patterns in forest disturbance ecology. Some may be more important than others in certain contexts, but the findings of the present study indicated that no single factor has pervasive importance over the others. Rather, these factors are tightly intertwined in a complex way, that these factors often complement each other, and that they contribute simultaneously to the overall susceptibility to and patterns of windstorm damage. In summary, even a slight change in one factor (e.g., stand structure, time since last disturbance, and past thinning practice) may have cascading effects on the others, thereby producing diverging patterns and drivers of windstorm damage among forest stands or over time. These points are reminiscent of the earlier argument proposed by Gardiner and Quine (2000), i.e., it is difficult to make general statements about expected wind damage patterns, and thus, the response of management should be "context sensitive."

\section{Additional file}

\begin{abstract}
Additional file 1: Table S1. Classification of main tree species into shade tolerance classes. Figure S1. (a) The location of the Big Thicket National Preserve (BTNP) in east Texas. The inset indicates (b), that is, the Turkey Creek Unit showing the distribution of the five plots $(40 \times 50 \mathrm{~m})$. Figure S2. Spatial distribution of individual trees at the five plots $(40 \times$ $50 \mathrm{~m}$ ) established in the Turkey Creek Unit of the Big Thicket National Preserve, Texas, USA. In each parenthesis, the first value indicates the number of all recorded trees and the second value represents the number of the trees that were directly damaged during Hurricane Rita. Figure S3. Species composition in the five plots $(40 \times 50 \mathrm{~m})$ established in the Turkey Creek Unit of the Big Thicket National Preserve, Texas, USA ( $\mathrm{Pi}$ ta $=$ Pinus taeda, Li st = Liquidambar styraciflua, Qu ni = Quercus nigra, Qu al = Quercus alba, II op = Ilex opaca, Mg gr = Magnolia grandiflora).
\end{abstract}

\section{Abbreviations}

ANOVA: Analysis of variance; BTNP: Big Thicket National

PreserveDBHDiameter at breast height; HD: Height-to-diameter ratio; $\mathrm{HTT}$ : Height to the top of the canopy

\section{Acknowledgements}

We appreciate field assistance from Will Flatley, Laura Spanel-Weber, and Amanda Young.

\section{Authors' contributions}

ACM and CWL conceived the work. DK, ACM, and CWL performed field work. DK conducted data analysis and wrote the manuscript. All the authors approved the submission of the manuscript in its current form.

\section{Funding}

Daehyun Kim was supported by the Research Resettlement Fund for the new faculty of Seoul National University. 


\section{Availability of data and materials}

All data involved in this study are provided by the authors upon request.

\section{Ethics approval and consent to participate}

Fieldwork was conducted under United States National Park Service permit BITH-00014.

\section{Consent for publication}

Not applicable.

\section{Competing interests}

The authors declare that they have no competing interests.

\section{Author details}

'Department of Geography, Seoul National University, Seoul 08826, South Korea. ${ }^{2}$ Institute for Korean Regional Studies, Seoul National University, Seoul 08826, South Korea. ${ }^{3}$ College of Science and Engineering, Flinders University, Bedford Park, SA 5042, Australia. ${ }^{4}$ Department of Geography, Texas A\&M University, College Station, TX 77843, USA.

Received: 21 July 2019 Accepted: 18 October 2019

Published online: 27 November 2019

\section{References}

Allen MS, Thapa V, Thapa V, Arévalo JR, Palmer MW. Windstorm damage and forest recovery: accelerated succession, stand structure, and spatial pattern over 25 years in two Minnesota forests. Plant Ecol. 2012;213:1833-42.

Ancelin P, Courbaud B, Fourcaud T. Development of an individual tree-based mechanical model to predict wind damage within forest stands. Forest Ecol Manag. 2004;203:101-21.

Batista WB, Platt WJ. Tree population responses to hurricane disturbance: syndromes in a south-eastern USA old-growth forest. J Ecol. 2003;91:197-212.

Burns RM, Honkala BH. Silvics of North America: Vol. 2. Hardwoods. USDA Agricultural: Washington; 1990.

Canham CD, Papaik MJ, Latty EF. Interspecific variation in susceptibility to windthrow as a function of tree size and storm severity for northern temperate tree species. Can J For Res. 2001;31:1-10.

Churchill DJ, Larson AJ, Dahlgreen MC, Franklin JF, Hessburg PF, Lutz JA. Restoring forest resilience: from reference spatial patterns to silvicultural prescriptions and monitoring. Forest Ecol Manag. 2013;291:442-57.

Clinton BD, Baker CR. Catastrophic windthrow in the southern Appalachians: characteristics of pits and mounds and initial vegetation responses. Forest Ecol Manag. 2000;126:51-60.

Condit R, Ashton PS, Baker P, Bunyavejchewin S, Gunatilleke S, Gunatilleke N, Hubbell SP, Foster RB, Itoh A, LaFrankie JV, Lee HS, Losos E, Manokaran N, Sukumar R, Yamakura T. Spatial patterns in the distribution of tropical tree species. Science. 2000;288:1414-8.

Cremer KW, Borough CJ, McKinnell FH, Carter PR. Effects of stocking and thinning on wind damage in plantations. New Zeal J For Sci. 1982;12:244-68.

Egbäck S, Bullock BP, Isik F, McKeand SE. Height-diameter relationships for different genetic planting stock of loblolly pine at age 6. For Sci. 2015;61: 424-8.

Everham EM, Brokaw NVL. Forest damage and recovery from catastrophic wind. Bot Rev. 1996;62:113-85.

Foster DR. Species and stand response to catastrophic wind in central New England. USA J Ecol. 1988;76:135-51.

Foster DR, Boose ER. Patterns of forest damage resulting from catastrophic wind in central New England. USA J Ecol. 1992;80:79-98.

Franklin JF, Spies TA, van Pelt R, Carey AB, Thornburgh DA, Berg DR, Lindenmayer DB, Harmon ME, Keeton WS, Shaw DC, Bible K, Chen J. Disturbances and structural development of natural forest ecosystems with silvicultural implications, using Douglas-fir forests as an example. Forest Ecol Manag. 2002:155:399-423.

Gardiner B, Marshall B, Achim A, Belcher R, Wood C. The stability of different silvicultural systems: a wind-tunnel investigation. Forestry. 2005;78:471-84.

Gardiner BA, Quine CP. Management of forests to reduce the risk of abiotic damage - a review with particular reference to the effects of strong winds. Forest Ecol Manag. 2000;135:261-77.

Gardiner BA, Stacey GR, Belcher RE, Wood CJ. Field and wind tunnel assessments of the implications of respacing and thinning for tree stability. Forestry. 1997; 70:233-52.
Glitzenstein JS, Harcombe PA. Effects of the December 1983 tornado on forest vegetation of the Big Thicket, southeast Texas. USA Forest Ecol Manag. 1988; 25:269-90.

Green SR, Grace J, Hutchings NJ. Observations of turbulent air flow in three stands of widely spaced Sitka spruce. Agric For Meteorol. 1995;74:205-25.

Gresham CA, Williams TM, Lipscomb DJ. Hurricane Hugo wind damage to southeastern U.S. coastal forest tree species. Biotropica. 1991;23:420-6.

Grime JP. Plant strategies, vegetation processes, and ecosystem properties. 2nd ed. New York: Wiley; 2001.

Haase P. Spatial pattern analysis in ecology based on Ripley's K-function: introduction and methods of edge correction. J Veg Sci. 1995;6:575-82.

Hale SE, Gardiner BA, Wellpott A, Nicoll BC, Achim A. Wind loading of trees: influence of tree size and competition. Eur J For Res. 2012;131:203-17.

Harcombe PA, Leipzig LEM, Elsik IS. Effects of Hurricane Rita on three long-term forest study plots in east Texas, USA. Wetlands. 2009;29:88-100.

Kim D, Campbell JJN. Effects of tree size, shade-tolerance, and spatial pattern on the mortality of woody plants in a semi-natural urban woodlot, central Kentucky, USA. Prof Geogr. 2016;68:436-50.

Kooch Y, Hosseini SM, Šamonil P, Hojjati SM. The effect of windthrow disturbances on biochemical and chemical soil properties in the northern mountainous forests of Iran. Catena. 2014;116:142-8.

Lafon CW. Forest disturbance by ice storms in Quercus forests of the southern Appalachian Mountains, USA. Écoscience. 2006;13:30-43.

Long JN. Emulating natural disturbance regimes as a basis for forest management: a North American view. Forest Ecol Manag. 2009;257:1868-73.

Marks PL, Harcombe PA. Forest vegetation of the Big Thicket, southeast Texas. Ecol Monogr. 1981;51:287-305.

Mason WL. Are irregular stands more windfirm? Forestry. 2002;75:347-55.

Milne R. Modelling mechanical stresses in living Sitka spruce stems. In: Coutts MP, Grace J, editors. Wind and trees. Cambridge: Cambridge University Press; 1995. p. 165-81.

Mitchell SJ. Wind as a natural disturbance agent in forests: a synthesis. Forestry. 2013;86:147-57.

NOAA (National Oceanic and Atmospheric Administration) Data tools: 1981-2010 Normal. [https://www.ncdc.noaa.gov/cdo-web/datatools/normals] Accessed 27 Sept 2017.

Oliver WW. Twenty-five-year growth and mortality of planted ponderosa pine repeatedly thinned to different stand densities in northern California. West J Appl For. 1997;12:122-30.

Peltola H, Kellomäki S. A mechanistic model for calculating windthrow and stem breakage of Scots pines at stand edge. Silva Fenn. 1993;27:99-111.

Peterson CJ. Damage and recovery of tree species after two different tornadoes in the same old growth forest: a comparison of infrequent wind disturbances. Forest Ecol Manag. 2000;135:237-52.

Pinkard EA, Neilsen WA. Crown and stand characteristics of Eucalyptus nitens in response to initial spacing: implications for thinning. Forest Ecol Manag. 2003:172:215-27.

Reukema DL. Forty-year development of Douglas-fir stands planted at various spacings. In: USDA Forest Service Research Paper. PNW-100; 1970. p. 21.

Reukema DL. Fifty-year development of Douglas-fir stands planted at various spacings. In: USDA Forest Service Research Paper. PNW-253; 1979. p. 21.

Rich RL, Frelich LE, Reich PB. Wind-throw mortality in the southern boreal forest: effects of species, diameter and stand age. J Ecol. 2007:95:1261-73.

Ruck B, Frank C, Tischmacher M. On the influence of windward edge structure and stand density on the flow characteristics at forest edges. Eur J For Res. 2012;131:177-89.

Santos LT, Marra DM, Trumbore S, de Camargo PB, Negrón-Juárez RI, Lima AJN, Ribeiro GHPM, Santos J, Higuchi N. Windthrows increase soil carbon stocks in a central Amazon forest. Biogeosciences. 2016;13:1299-308.

Schindler D, Bauhus J, Mayer H. Wind effects on trees. Eur J For Res. 2012;131: $159-63$.

Sokal RR, Rohlf FJ. Biometry: the principles and practice of statistics in biological research. New York: W H Freeman; 1995.

Stearns SC. The evolution of life histories. Oxford: Oxford University Press; 1992.

Ulanova NG. The effects of windthrow on forests at different spatial scales: a review. Forest Ecol Manag. 2000;135:155-67.

Uriarte M, Papaik M. Hurricane impacts on dynamics, structure and carbon sequestration potential of forest ecosystems in southern New England, USA. Tellus A. 2007;59:519-28.

Valinger E, Fridman J. Modelling probability of snow and wind damage in Scots pine stands using tree characteristics. Forest Ecol Manag. 1997;97:215-22. 
Valladares F, Niinemets Ü. Shade tolerance, a key plant feature of complex nature and consequences. Annu Rev Ecol Evol S. 2008:39:237-57.

Webb SL. Windstorm damage and microsite colonization in two Minnesota forests. Can J For Res. 1988:18:1186-95.

Webb SL. Contrasting windstorm consequences in two forests, Itasca State Park, Minnesota. Ecology. 1989;70:1167-80.

Wiegand T, Moloney KA. Rings, circles, and null-models for point pattern analysis in ecology. Oikos. 2004;104:209-29.

Wiegand T, Moloney KA. Handbook of spatial point pattern analysis in ecology. Boca Raton: Chapman and Hall/CRC press; 2013.

Wolf A, Møller PF, Bradshaw RHW, Bigler J. Storm damage and long-term mortality in a semi-natural, temperate deciduous forest. Forest Ecol Manag. 2004;188:197-210.

Wonn HT, O'Hara KL. Height:diameter ratios and stability relationships for four northern Rocky Mountain tree species. West J Appl For. 2001;16:87-94.

Xi W, Peet RK. The complexity of catastrophic wind impacts on temperate forests. In: Lupo A, editor. Recent hurricane research - climate, dynamics, and societal impacts. Shanghai: InTech; 2011. p. 503-34.

Xi W, Peet RK, Decoster JK, Urban DL. Tree damage risk factors associated with large, infrequent wind disturbances of Carolina forests. Forestry. 2008;81:317-34.

Zeng H, Peltola H, Talkkari A, Venäläinen A, Strandman H, Kellomäki S, Wang K. Influence of clear-cutting on the risk of wind damage at forest edges. Forest Ecol Manag. 2004;203:77-88.

\section{Publisher's Note}

Springer Nature remains neutral with regard to jurisdictional claims in published maps and institutional affiliations.

Ready to submit your research? Choose BMC and benefit from:

- fast, convenient online submission

- thorough peer review by experienced researchers in your field

- rapid publication on acceptance

- support for research data, including large and complex data types

- gold Open Access which fosters wider collaboration and increased citations

- maximum visibility for your research: over $100 \mathrm{M}$ website views per year

At BMC, research is always in progress.

Learn more biomedcentral.com/submissions 